\title{
Management of Fluid Status in Haemodialysis Patients: The Roles of Technology and Dietary Advice
}

\author{
Elizabeth Lindley, Lynne Aspinall, Claire Gardiner and Elizabeth Garthwaite \\ Department of Renal Medicine, Leeds Teaching Hospitals NHS Trust \\ United Kingdom
}

\section{Introduction}

The kidneys play a vital role in maintaining normal tissue hydration and serum sodium level. In haemodialysis patients, with impaired or absent kidney function, fluid status is managed by removing excess fluid using ultrafiltration and by restricting dietary sodium intake. Ideally, haemodialysis patients should remain close to normal hydration throughout the interdialytic period, with minimal periods of excessive dehydration or fluid overload and with no fluid-related co-morbidity.

Optimal fluid management is achieved by adjusting the post-dialysis 'target' weight and, where necessary, limiting the fluid gained between dialysis sessions. While clinical history and examination remain the basis for prescribing the target weight, technology can provide useful objective information especially where the clinical indications are ambiguous. A simple non-invasive test can now be carried out when a patient attends for dialysis enabling staff to pick up changes in body composition so that their target weight can be adjusted to maintain optimal fluid status.

In most patients, interdialytic fluid gain (IDFG) is directly related to sodium intake. Acceptable fluid gains can usually be achieved by limiting salt intake to the recommended daily allowance for the general population and avoiding unnecessary sodium loading during dialysis. Low pre-dialysis serum sodium levels can help identify patients with other causes of high IDFG, such as high blood sugar or social drinking, who need additional counselling. For the patients, lowering sodium intake may also improve blood pressure control and reduce requirements for antihypertensive medication. Staff education, and preferably participation, is vital when implementing salt restriction in a haemodialysis unit.

\section{Optimisation of the target weight}

\subsection{What is meant by target weight?}

A typical definition found on patient-focussed websites is 'the weight your doctor thinks you would be when all the extra fluid is removed from your body'(DaVita, n.d.). This actually defines the 'normally hydrated' weight which is a very useful concept but not necessarily the weight the patient should achieve post-dialysis. 
Most publications aimed at professionals define the target weight as the lowest weight a patient can tolerate without the development of symptoms or hypotension (Henderson, 1980). Variations of this definition have appeared in publications for over 30 years though it is unhelpful in those patients who are hypotensive when clearly fluid overloaded based on other clinical assessments. It also suggests that patients should be dehydrated to the point at which they become symptomatic regardless of the effect on residual renal function (RRF).

The importance of preserving RRF is undisputed in peritoneal dialysis (Marrón et al, 2008) but, until recently, it has been widely assumed that RRF is of no significance once a patient has started haemodialysis. Bioincompatible membranes and contaminated dialysis fluid probably did contribute to accelerated loss of RRF in haemodialysis. However with modern technology both single centre (Vilar et al, 2009) and national (van der Wal et al, 2011) studies have shown that RRF can be preserved in haemodialysis, and that loss of RRF is a powerful a predictor of mortality (Brener et al, 2010).

A more holistic definition of target weight is the post-dialysis weight that enables the patient to remain close to normal hydration throughout the interdialytic period, without experiencing discomfort or compromising residual function.

\subsection{Clinical indicators of hydration status}

Regular clinical assessments are an essential element in the overall management of haemodialysis patients. Table 1 lists the parameters that are typically used to assess fluid status and which should be reviewed regularly whether or not there are concerns about the patient's fluid status.

\begin{tabular}{|c|c|c|}
\hline Parameter & Fluid overload & Fluid depletion \\
\hline Trend in body weight & $\begin{array}{l}\text { Recent weight loss } \\
\text { Anorexia, hospital admission } \\
\text { Nausea, vomiting, diarrhoea }\end{array}$ & $\begin{array}{l}\text { Recent weight gain } \\
\text { Improved appetite } \\
\text { Nutritional support started }\end{array}$ \\
\hline Residual renal function & Usually minimal or absent & May be significant \\
\hline Blood pressure & May be elevated & May be low \\
\hline Neck veins & Full & Usually flat \\
\hline Breathing & $\begin{array}{l}\text { May be breathless } \\
\text { May be unable to lie flat }\end{array}$ & Usually breathing normally \\
\hline Oedema & $\begin{array}{l}\text { May have facial oedema } \\
\text { May have ankle/hand oedema }\end{array}$ & No generalised oedema \\
\hline Intradialytic problems & $\begin{array}{l}\text { May have intradialytic } \\
\text { hypotension }\end{array}$ & $\begin{array}{l}\text { May be unable to achieve target weight } \\
\text { May have cramps, dizziness }\end{array}$ \\
\hline Post-dialysis problems & $\begin{array}{l}\text { Usually recovers quickly } \\
\text { May have headaches }\end{array}$ & $\begin{array}{l}\text { Usually feels washed out } \\
\text { May be thirsty, have croaky voice }\end{array}$ \\
\hline Chest X-ray (if available) & May show enlarged heart & Usually shows normal heart \\
\hline
\end{tabular}

Table 1. Parameters used in a typical clinical assessment of fluid status

Unfortunately haemodialysis patients often have co-morbidity that can make the signs of fluid status ambiguous. Heart failure can lead to low blood pressure in a patient with severe 
fluid overload while an inadequately blocked renin-angiotensin system can lead to high blood pressure in a patient who is dehydrated. Many patients with fluid overload show no obvious signs of oedema and have no breathing difficulties, while chest infections or anaemia can cause breathlessness in fluid depleted patients.

Where the clinical assessment is not straightforward, as in the patient who is hypotensive but clearly oedematous, technology can provide objective information to help inform the appropriate adjustment of target weight (Charra, 2007; Jaeger and Metha, 1999). This chapter covers the technology that is commercially available and intended for routine use in the out-patient haemodialysis setting.

\subsection{Continuous blood volume monitoring}

Blood volume monitoring (BVM) was introduced in the 1990's. The monitors used ultrasonic or optical sensors to measure changes in haematocrit in the arterial blood line. An increase in haematocrit during dialysis indicates a decrease in blood volume. BVM was intended to alert staff (or automatically adjust the machine) when poor refilling of the intravascular space from the tissues led to an excessive drop in blood volume as fluid was removed by ultrafiltration. However, on introducing BVM, many units found a significant proportion of the patients appeared to be chronically fluid overloaded.

When fluid accumulates in the body, most of the excess is contained in the extracellular space. Figure 1 shows how the blood volume changes as the extracellular fluid volume increases. Initially there is a steady increase in blood volume, but at about 7 litres the intravascular space is unable to accommodate any more fluid and the blood volume remains constant and all additional fluid is stored in the tissues. If the BVM shows no change in blood volume while a significant amount of fluid is removed, this gives a clear diagnosis of severe fluid overload. When BVM was introduced in St James's Hospital in Leeds, approximately $20 \%$ of patients were found to be overloaded on the first measurement. They were usually asymptomatic with blood pressure controlled using medication. In most cases the patient's target weight was successfully decreased.

The 'flat-line' BVM when removing fluid gives an unequivocal indication of fluid overload. A falling BVM trace has to be interpreted with caution for a number of reasons. At best, the BVM can only tell you how easily the patient is refilling as fluid is removed. A patient may be overloaded but not refilling adequately which could lead staff to believe they are normally hydrated or dry. Redistribution of blood from the central to the micro-circulation (e.g. to the splanchnic circulation when eating) can look like a rapid drop in blood volume. This is because the lower haematocrit in capillaries causes haemoconcentration in the central vessels (Mitra et al, 2004) from which the blood is taken to the dialysis machine. Patients may become symptomatic as a result of redistribution of blood, but the solution is not to increase target weight.

Other problems that can occur when using BVM to assess fluid status are interpretation of overhydration in patients with good residual function who have minimal change in blood volume because they required little fluid removal, and confusing dehydration with normal hydration. The latter occurs because, as shown in figure 1, the rate of change in blood volume with extracellular fluid removal is the same above and below normal hydration.

Misinterpretation of BVM traces may have contributed to the higher mortality observed in patients randomised to receive optional BVM measurements in the CLIMB study (Reddan et al, 2005). With adequate training, BVM can help in the assessment of fluid status but it is best used to identify and implement fluid removal strategies that minimise symptoms. 


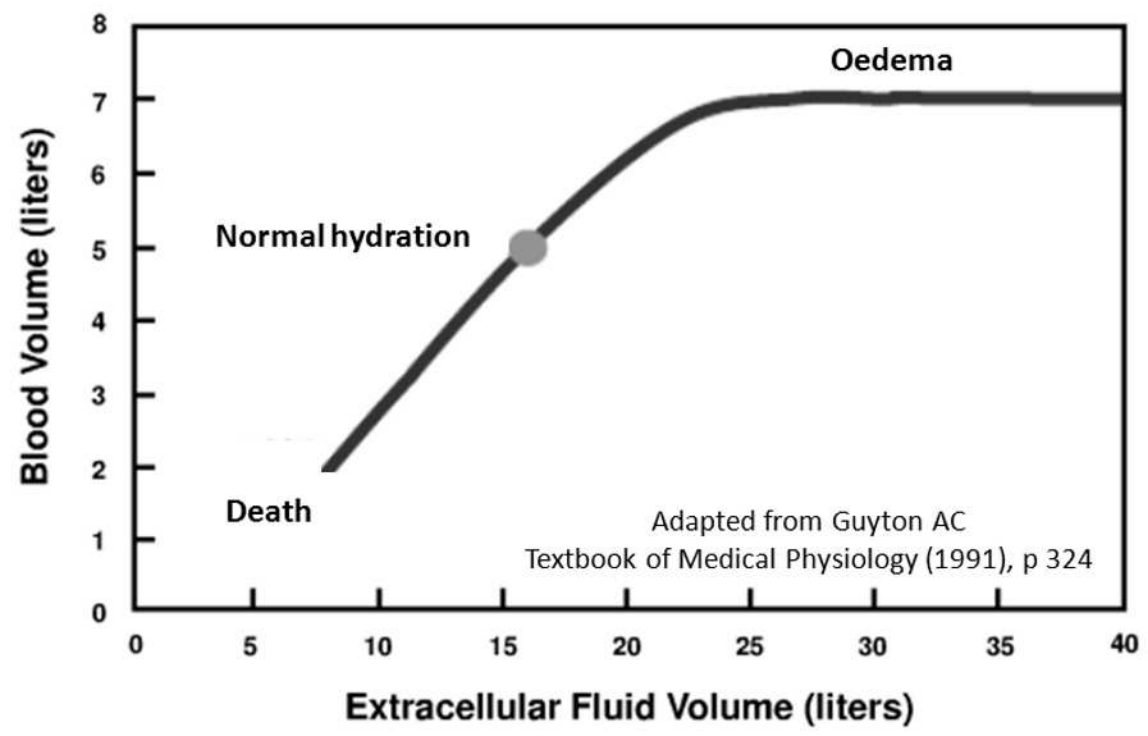

Fig. 1. Variation in blood volume with extracellular volume

\subsection{Bioimpedance and body composition monitoring}

Bioimpedance monitors can provide quick, cheap, non-invasive bedside measurements of fluid status with good reproducibility. However, until recently the use of bioimpedance has been restricted to a relatively small number of centres with both a clinical and an academic interest in the technology.

In 'single frequency' bioimpedance monitors, a tiny $50 \mathrm{kHz}$ alternating current is passed between a pair of electrodes, usually placed on the hand and foot. Sensing electrodes, placed just inside the current carrying electrodes, measure 'resistance' and 'reactance' to the passage of the current. Resistance and reactance combine to give the overall 'impedance'. An increase in body water makes it easier for current to pass through the body so that resistance decreases. Reactance, which is due to the capacitance of cell membranes, decreases as the number and/or integrity of the membranes decreases.

Single frequency bioimpedance monitors are widely used in health clubs as they can give an estimate of body fat and muscle mass. The technology is also built into bathroom scales where the current is passed between the feet. In dialysis patients, the equations used to derive body composition from the impedance at $50 \mathrm{kHz}$ are unreliable if the patient has an abnormal fluid status.

Prof Antonio Piccoli and co-workers recognised this and developed bioimpedance vector analysis (BIVA) which simply looks at the hydration of the body tissues between electrodes placed on the hand and foot. The resistance and reactance measurements are normalised to height and interpreted using gender-specific nomograms derived from large studies of normal subjects and of populations with altered body composition (Piccoli 1994, 1995). As shown in figure 2, fluid overload is associated with movement of the vector downward and to the left whilst dehydration moves the vector up and to the right. 


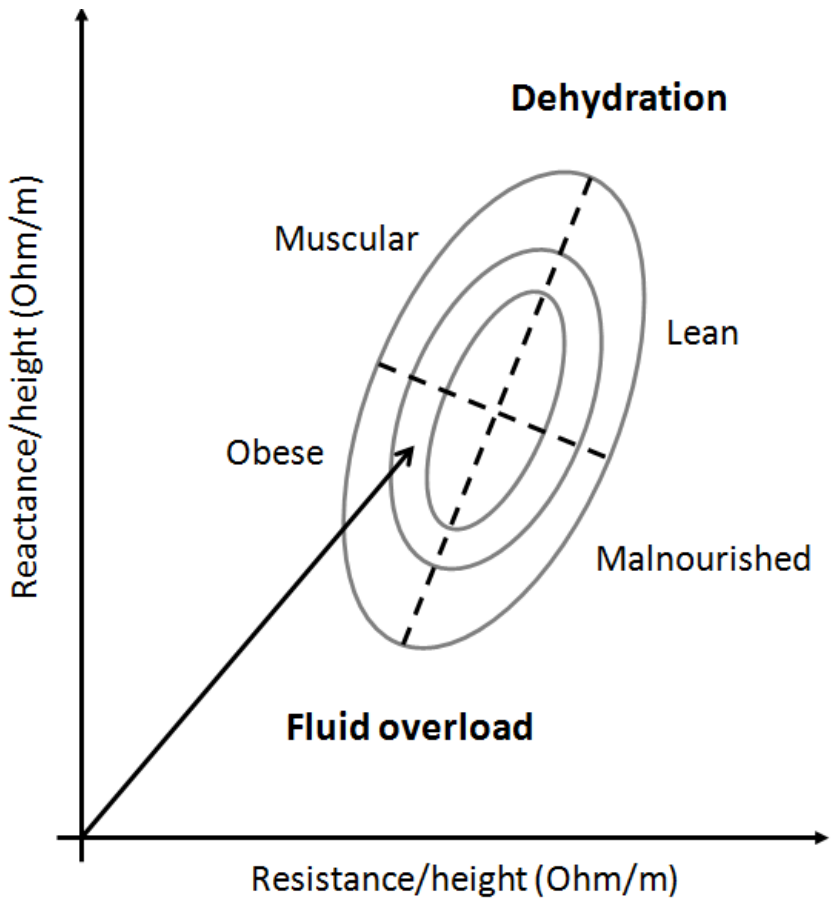

Fig. 2. Nomogram used for interpreting single frequency bioimpedance measurements. The outer ellipse encloses $95 \%$ of readings for normal subjects.

BIVA could provide practical information on changes in fluid status using very simple equipment that would cost little more than a set of bathroom scales if the market was larger. The reason BIVA cannot give an accurate indication of the patient's normally hydrated weight is clear when you examine Figure 2. The vector shown could be obtained from a slightly overweight subject with normal hydration, from a muscular subject with fluid overload or from an obese subject who is dehydrated. The confusion arises because adipose tissue contains very little intracellular water as fat cells are filled with triglycerides, but does have water in the extracellular space. So, like overhydration, an increase in body fat leads to an increase in the proportion of fluid in the extracellular space leading to a shorter vector. In whole body bioimpedance spectroscopy (BIS), the electrodes are placed as for BIVA and resistance and reactance is measured over a range of frequencies. The results, together with the height, weight and gender of the subject, are used to compute the intracellular and extracellular water volumes (ECW and ICW). Fluid overload is associated with an increase in the proportion of water in the extracellular space but until recently, it was necessary for the user to decide what this proportion should be at normal hydration. There are a number of published methods for doing this (for example Lindley et al, 2005; Lopot et al, 2002) but they involve comparing dialysis patients with normal controls. As with BIVA, this makes it difficult to assess fluid status in patients with abnormal body composition.

Body composition monitoring (BCM) is the most recent commercially available development in bioimpedance monitoring. It uses the same electronic measurements as BIS to determine ECW and ICW but incorporates additional modelling (Moissl et al, 2006; Chamney et al, 2007) to take account of the amount of body fat the patient actually has, 
rather than assuming they have the average amount for a person of their age and gender. Essentially, the BCM model assumes that the body is composed of normally hydrated lean tissue, normally hydrated adipose tissue and excess fluid (or missing fluid if the patient is dehydrated). For any combination of ECW, ICW and weight, there is only one matching combination of lean tissue, fat and excess/missing fluid.

With BCM, we can get an estimate of normal hydration and, for the first time, select a target weight that minimises the unwanted effects of dehydration as well as those of overhydration. Just as the introduction of BVM revealed a cohort of chronically overloaded patients, introducing BCM as part of the assessment of fluid status identified a group who were excessively dehydrated. In some of the cases identified in this way, an increase in target weight led to a reduction in interdialytic fluid gain as the patient's kidneys were able to produce more urine.

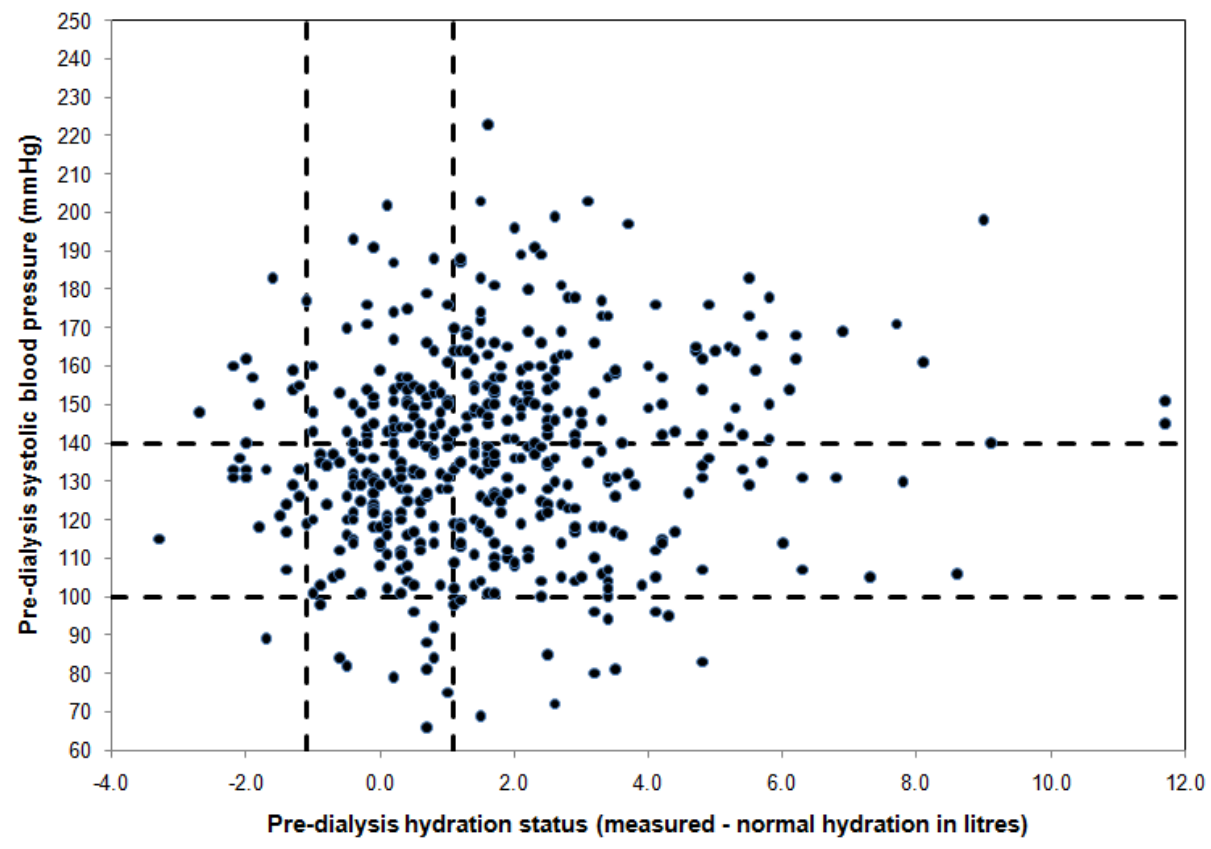

Fig. 3. Pre-dialysis systolic blood pressure vs hydration status

Users of BCM soon become aware that blood pressure can be misleading when evaluating fluid status. The scatter plot in Figure 3 shows the relationship between pre-dialysis systolic blood pressure and hydration status (the difference between measured and normal hydration in litres), for the first BCM measurement made in 474 haemodialysis patients under the care of Leeds Teaching Hospitals. A very similar plot was obtained in a crosssectional study of 639 PD patients (Van Biesen et al, 2010). The expected increase in blood pressure with fluid overload is present, but only as a trend for the population. For an individual patient, a single high or low blood pressure measurement is a rather poor predictor of fluid status, though a trend to higher or lower blood pressures in the same patient does provide important clinical information.

A significant number of patients who are normally hydrated, or even dehydrated, predialysis have high blood pressure. The traditional method for treating these patients by 
systematically decreasing their target weight could compromise their residual renal function, cause cramps and leave them feeling exhausted for hours after dialysis.

When the BCM measurement is combined with the clinical indicators in Table 1, and knowledge of the patient's usual IDFG, it is possible to customise the target weight as described in 2.1. Introducing BCM has been shown to improve blood pressure control and reduce intradialytic adverse events (Machek, 2010). Ideally BCM should be carried out at least quarterly, though more frequent measurements will be needed for patients who are unwell (especially if admitted to hospital) or who are trying to gain or lose weight. As well as ensuring timely adjustments to the prescribed target weight, BCM gives valuable information on changes in body fat and lean tissue and provides an accurate urea distribution volume for use in on-line measurements of dialysis adequacy.

\section{Control of interdialytic fluid gain (IDFG)}

\subsection{Salt and fluid balance: Osmometric thirst and the sodium 'set-point'}

The patient's hydration status during the interdialytic period depends on both the weight achieved after dialysis and the fluid gained by the patient before the next session. Very high IDFG can make it impossible for the patient to remain close to normal hydration and to control pre-dialysis blood pressure. Another problem, particularly in elderly and malnourished patients, is the inability to tolerate the ultrafiltration rates required to remove a moderate volume of accumulated fluid. Whether the patient is gaining excessive volumes or failing to transfer fluid from the tissues into the circulation sufficiently rapidly, the solution is to try and reduce their IDFG.

A typical haemodialysis patient in the UK accumulates about 2 litres of excess fluid in the intervals between sessions. When they attend for dialysis the machine is programmed to remove the excess fluid by ultrafiltration. Every litre removed in this way will carry with it about $137 \mathrm{mmol}$ of sodium ions, though the actual amount will depend on the serum sodium level at the time the fluid was removed. As $137 \mathrm{mmol}$ is the amount of sodium in $8 \mathrm{~g}$ of salt, the typical UK patient loses sodium equivalent to about $16 \mathrm{~g}$ of salt at each dialysis session. The body does have 'non-osmotic' sodium stores in tissues such as the skin and connective tissues (Titze, 2008) and it is possible that sodium can be recruited into or removed from these stores to buffer short term fluctuations in serum sodium. However, if the patient is assumed to be in steady state on the timescale of the interdialytic period, they must be making up for the sodium lost by taking in the equivalent of $16 \mathrm{~g}$ of salt between sessions. Sodium does come in other forms other than salt, such as sodium bicarbonate, but it is usually combined with chloride.

If retained in the body, the salt taken in will cause 'osmometric' thirst. Osmometric thirst is triggered when increased osmolarity of the extracellular fluid causes osmoreceptor cells in the hypothalamus to shrink. Volumetric thirst, which occurs when the body loses both water and salt, is triggered when baroreceptors in the atria sense low cardiac return volume. Haemodialysis patients may experience volumetric thirst immediately after dialysis if they are dehydrated, but at other times their thirst is primarily osmometric. Fluid drunk in response to post-dialysis dehydration does not usually lead to increased IDFG as it simply delays osmometric thirst until the patient has consumed enough salt. An important exception to this occurs if a patient with good residual renal function is dehydrated, as they will need to take in enough fluid to normalise their hydration before diuresis starts.

Osmometric thirst is part of the body's system for maintaining electrolyte balance. If our typical haemodialysis patient is anuric (unable to lose sodium via the kidneys), they will need to take in about one litre of water to dilute every $8 \mathrm{~g}$ salt consumed to a normal 
physiological level. The patient will consume fluid with their food, when taking medications and in beverages taken socially. They may not even be aware of feeling thirsty, although many haemodialysis patients do find thirst a problem, but if salt consumption gets ahead of fluid intake, osmometric thirst will force the patient to drink enough to restore their serum sodium to an acceptable level. This level varies between patients and has been called the sodium 'set-point' or the 'osmostat' (Keen \& Gotch, 2007).

Patients who take in no more fluid than is needed to avoid (or satisfy) salt-induced thirst will present for dialysis with a relatively constant serum sodium. Figure 4 shows predialysis serum sodium averaged over 12 months for 375 haemodialysis patients in the care of the Leeds Teaching Hospitals (Gardiner et al, 2006). The majority of patients appear to have a well defined sodium set point that lies within the normal range of 135 to $145 \mathrm{mmol} / \mathrm{l}$. The patients with relatively high pre-dialysis sodium levels could have a high set-point, but they could also be overriding their thirst to limit fluid gain or be unable to drink freely.

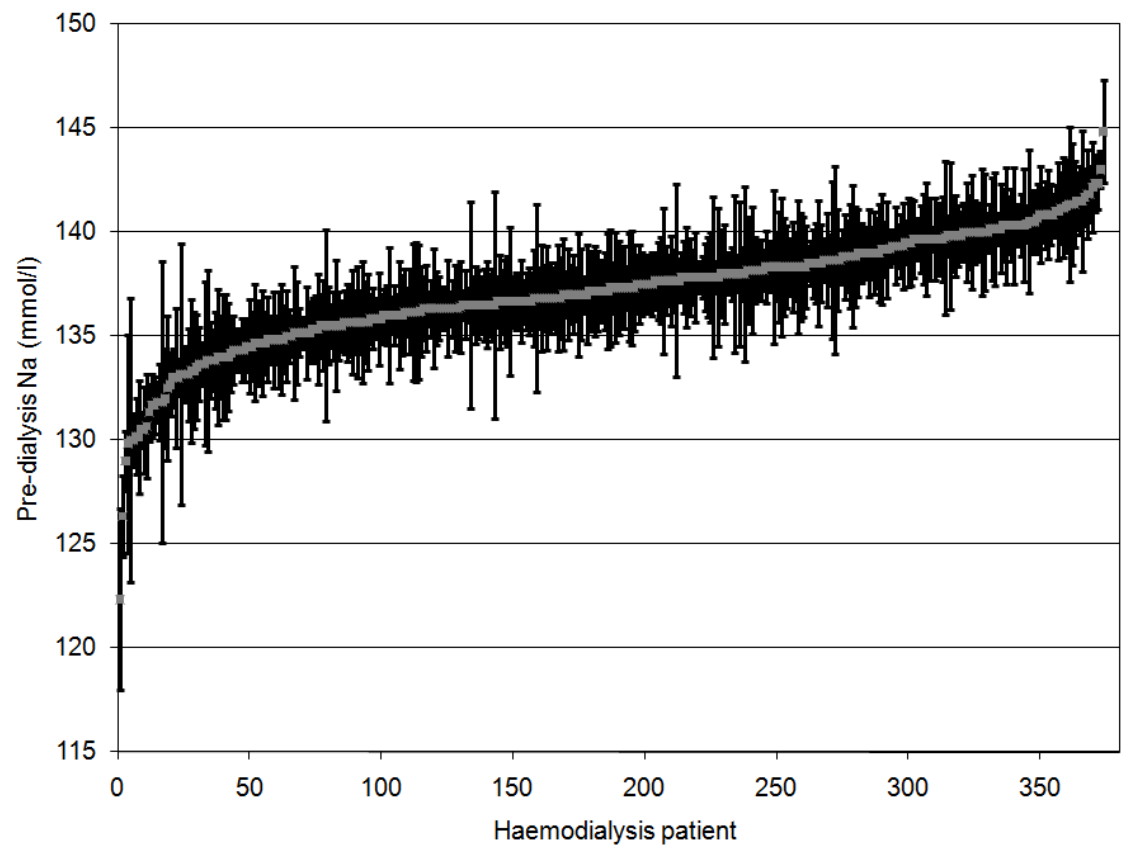

Fig. 4. Pre-dialysis serum sodium level for $375 \mathrm{HD}$ patients. Each bar represents the distribution (mean and standard deviation) of 6 monthly measurements in a single patient.

Low pre-dialysis serum sodium may be due to urinary losses, but this will normally be associated with low IDFG. In patients with low sodium and high IDFG, elevated blood sugar may be responsible. In the group shown in Figure 4, the 28 poorly controlled diabetics (glycosylated haemoglobin $>7 \%$ ) had lower serum sodium (136 vs. $137 \mathrm{mmol} / \mathrm{l}, \mathrm{p}=0.03$ ) and higher fluid gain (2.3 vs. $1.7 \mathrm{~kg}, \mathrm{p}=0.01$ ) compared to well controlled diabetics and nondiabetics. However, the lowest pre-dialysis sodium levels occurred in non-diabetic patients with relatively high IDFG. These patients are taking in excess free water for various reasons including xerostomia (dry mouth, often due to medications), and comfort or social drinking. While patients with high IDFG and low pre-dialysis sodium will benefit from dietary salt restriction, other factors leading to fluid intake should be investigated and resolved if possible. 


\subsection{Minimising sodium loading during dialysis}

During dialysis, sodium diffuses between the dialysate and the plasma water across the dialyser membrane until equilibrium is achieved. The plasma contains negatively charged proteins that are too large to pass through the dialyser membrane. This leads to retention of positively charged ions like sodium in the plasma water to maintain electric neutrality. This trapping of positively charged ions by negatively charged proteins leads to a higher concentration of sodium in the plasma water than in the dialysate at equilibrium (this is called the Gibbs-Donnan effect). Most labs measure the sodium concentration in the total plasma (the serum sodium), rather than the plasma water. Electrolytes in the total plasma are diluted by about $6 \%$ because of the volume taken up by the proteins and lipids. In most patients, this dilution more-or-less cancels out the Gibbs Donnan effect so that the measured serum sodium post-dialysis is usually close to the dialysate sodium level.

Through the plasma water, the sodium level in the patient's extracellular water equilibrates with the dialysate sodium during dialysis. Patients treated with dialysate sodium that is higher than their pre-dialysis serum level will receive an infusion of sodium during dialysis. Consider an anuric $70 \mathrm{~kg}$ male patient whose set point leads him to come for dialysis with a serum sodium of around $137 \mathrm{mmol} / \mathrm{l}$. If he is treated with dialysate sodium of $140 \mathrm{mmol} / \mathrm{l}$, there will be a net transfer of between 45 and $100 \mathrm{mmol}$ of sodium from the dialysate to the patient during the session. The actual amount will depend on the movement of water out of the intracellular space to achieve osmotic equilibrium and transfers of other solutes. Although this sodium transfer is much smaller than the typical loss through ultrafiltration (about $275 \mathrm{mmol}$ for 2 litres removed), reducing the dialysate sodium by $3 \mathrm{mmol} / \mathrm{l}$ should lead to a decrease in IDFG of at least $0.3 \mathrm{~kg}$ in this patient.

To eliminate unnecessary intradialytic sodium loading, and avoid the associated fluid gain, individualisation of the dialysate sodium based on the patient's pre-dialysis serum or plasma water sodium level has been recommended (de Paula et al, 2004; Santos \& Peixoto, 2008). A simpler approach, which will achieve similar benefits in terms of reduced IDFG and blood pressure control, is to standardise the dialysate sodium levels towards the lower end of the normal range. Patients who normally have high serum sodium levels may experience osmotic disequilibrium (headache, nausea and hypertension) if treated with dialysate sodium of 135-137 mmol/l, but many will have no symptoms. Patients who have very low pre-dialysis sodium levels will gain sodium during dialysis, but this will not necessarily increase IDFG if their fluid intake is not controlled by osmometric thirst. Resetting of the sodium set-point, or 'osmostat', to very low levels has been reported (for example, as a complication of spinal cord injury) but it is rare and would lead to unbearable thirst after dialysis with dialysate sodium in the normal range.

\subsection{Recommended salt consumption}

Control of interdialytic fluid gains is important both in the maintenance of near-normal hydration and the minimisation of intradialytic hypotension and discomfort. Patients who consume less than $6 \mathrm{~g}$ of salt per day should accumulate no more than 0.81 of fluid per day (it takes $750 \mathrm{ml}$ of water to dilute $6 \mathrm{~g}$ salt to $137 \mathrm{mmol} / \mathrm{l}$ ). Most patients are able to tolerate the ultrafiltration rates required to remove this amount of fluid. Smaller patients and those with impaired autonomic function may need a tighter salt restriction, especially when they have three days between dialysis sessions.

Unlike most of the dietary restrictions placed on dialysis patients, the recommendation to limit salt intake applies to the whole population, including healthcare professionals! The World Health Organisation recommends a maximum salt intake of $5 \mathrm{~g} /$ day and regularly convenes meetings to discuss reducing salt consumption at population level (WHO, 2010). 
The USA, Canada, UK, Australia and New Zealand are among the countries that consider a recommended daily allowance (RDA) of $6 \mathrm{~g} /$ day to be achievable and sustainable. A salt intake of $6 \mathrm{~g} /$ day is equivalent to a sodium intake of $2.3 \mathrm{~g} /$ day or $100 \mathrm{mmol} /$ day.

The RDA for patients with kidney failure, as with all patients at high risk of cardiovascular disease, should probably be lower than for the general population. However, the practical and psychological benefit of having the same dietary restriction as family and carers, as well as the risk of malnutrition due to an unappetising diet, makes the national RDA a more realistic target for most patients.

\subsection{Dietary advice for patients}

Before counselling patients with problematic fluid gains, it is essential to review their serum sodium. Patients with high IDFG who have normal pre-dialysis sodium levels are drinking in response to osmometric thirst and must be given advice on reducing their salt intake. Simply telling these patients to restrict fluid intake, as is common in many dialysis units (Lindley et al, 2005), will not succeed in reducing IDFG (Tomson, 2001).

Patients with high IDFG and low pre-dialysis sodium should be assessed for other reasons for fluid intake, such as high blood glucose or social drinking. These patients will probably benefit from salt restriction but they will also require individualised interventions.

The first step in reducing salt intake is to understand where the salt is coming from. In industrialized countries, $75-80 \%$ of salt consumed comes from manufactured foods including butter, cheese, biscuits, pastry, cereals, snacks, processed meats, sauces and readymade soups and meals. In Canada, bread is reported to account for $14 \%$ of total dietary salt intake (WHO, 2010). Mhurchu et al report that bread purchased in the UK contain over $1 \mathrm{~g}$ of salt per 100g on average (Mhurchu et al, 2011). Restaurant meals and fast foods are frequently high in salt. In more rural populations, salt used as a preservative and added in cooking (usually in sauces) is the major source of salt in the diet. Fresh foods (meat, fish, vegetables) contribute $10 \%$ or less to salt intake.

\section{Tips to reduce salt (sodium)}

- Use fresh or frozen vegetables (if canned, look for low-sodium or no-salt-added on the label). If using food canned with salt, rinse the contents to remove as much as possible. Don't add salt to the water used for cooking.

- Try to use fresh poultry, fish and meat, rather than canned, smoked or processed products. Cheap processed meat often has salt added to make it absorb water and increase in weight.

- Cook rice, pasta and noodles without salt and avoid instant or flavoured products as they usually have added salt.

- Use ketchup, barbeque, soy and other sauces very sparingly.

- Make salad dressings and cooking sauces instead of buying them ready-made. Using other flavours (herbs, spices, lemon etc) may mean salt can be eliminated completely.

- Check nutrition labels on breakfast cereals, ready meals, soup and sauces to find products with lower salt/sodium. Food labelled as low in salt should contain less than $0.3 \mathrm{~g}$ of salt per serving, medium should mean 0.3 to $1.5 \mathrm{~g}$ per serving. Greater awareness of the need to reduce salt intake should increase the availability of low-salt products in the coming years, but always check that product labelled as lowsalt do not contain potassium-based salt substitutes.

Fig. 5. Tips on reducing salt intake based on the DASH brochure (US NHBLI, 2006). 
The importance of salt restriction for the whole population means that advice on lowering salt intake and recipes for low salt meals are widely available on the internet. The only modification required in dialysis patients is the need to be very careful of salt substitutes as they often contain potassium. Unfortunately the potassium content of processed food is often not clearly labelled. Figure 5 shows the tips for lowering salt intake from the 'Dietary Approaches to Stop Hypertension' brochure (US NHBLI, 2006) adapted for dialysis patients by a renal dietitian.

Patients who can tolerate only very limited fluid removal, and those who are hypertensive in the absence of fluid overload, may need to take further steps to reduce their salt consumption. This will include switching to unsalted butter and bread. If salt-free bread is not available, ways to substitute unsalted rice or pasta for bread should be sought. As these more stringent restrictions are difficult to implement, it is essential to prevent sodium loading during dialysis in these patients. Consideration should be given to lowering the dialysate sodium to $133-135 \mathrm{mmol} / 1$ and minimising infusion of normal saline (which contains $154 \mathrm{mmol} / \mathrm{l}$ sodium) at the end of dialysis (Penne et al, 2010).

Dialysis patients may have impaired taste sensitivity (Middleton 1999). If salt restriction leads to weight loss because the patient finds their food unappetising, they should be referred to a dietitian to look into the use of acceptable alternative flavourings. The need to check for weight loss and provide individual dietetic counselling is especially important in patients who need a very restricted salt intake as described above.

\subsection{Implementing salt restriction: Staff education}

There is a sound physiological basis for restricting intake of salt rather than fluids to control IDFG in most patients, though there are few published comparisons of the different approaches. Rupp et al compared patients on a traditional sodium and fluid restricted diet with those given a diet that just restricted sodium and found a significant decrease in IDFG only in the group on the simpler low-sodium diet (Rupp et al, 1978). Kayikcioglu et al compared cardiac function and blood pressure control in two units, one of which practiced a salt restriction strategy while the other relied on the use of anti-hypertensives (Kayikcioglu et al, 2009). The use of salt restriction not only reduced the requirement for antihypertensive medication (7\% vs. $42 \%)$, but led to significantly lower IDFG (2.29 vs. $3.31 \mathrm{~kg}$ ) and fewer episodes of intradialytic hypotension ( $11 \%$ vs. $27 \%)$.

With such clear benefits, it is surprising that there is not more emphasis on salt restriction in haemodialysis units. Patient information currently available via the internet tends to focus on fluid restriction, with advice such as using smaller cups, sipping slowly, sucking ice cubes or lemon wedges and keeping a fluid journal. The popularity of fluid restriction may be because fluid intake is relatively easy to monitor, while salt is hidden in manufactured foods and cutting out the 'visible' added salt has a disappointing impact on IDFG.

Dialysis staff can change the focus from fluid to salt restriction and establish a culture of sharing advice for reducing salt intake within the unit. With pressure from the World Health Organisation and national food safety bodies, we should see more low-salt products and increased disclosure of salt content. Tables of salt content in foods that can be used in educational material and quizzes are available from organisations such as the US Department of Agriculture (USDA, n.d.) and the Australian Healthy Eating Club (Healthy Eating Club, n.d.). Staff aiming to reduce their own salt intake to $<6 \mathrm{~g} /$ day will be able to swap tips rather than impose rules. How long does it take to get used to unsalted butter? Which breakfast cereals have the lowest salt content? How easy is it to make low salt bread? Haemodialysis patients with little or no residual renal function can get feedback on the impact of any dietary modification simply by monitoring their fluid gains. As a rough 
guide, every kilogram gained between dialysis sessions corresponds to an intake of $8 \mathrm{~g}$ of salt. So a $0.5 \mathrm{~kg}$ decrease in IDWG over the short break shows they have managed to reduce their salt intake by $4 \mathrm{~g}(2 \mathrm{~g} /$ day). Staff will need to carry out 24 hour urine collections to check their own salt consumption.

The link between low IDFG and poor survival is well established (Sezer et al, 2002) and haemodialysis patients are often at risk of malnutrition, so it is essential to ensure that what appears to be a successful intervention to reduce salt intake does not lead to undiagnosed weight loss and fluid overload.

\section{Conclusion}

The implementation of bioimpedance measurements to assist in the optimisation of the patient's target weight, and the use of salt restriction to avoid excessive fluid gains, should enable most haemodialysis patients to stay close to normal hydration throughout the interdialytic period.

Future research in the use of bioimpedance will include verification of the BCM models in patients at the extremes of body composition and with conditions leading to very abnormal fluid distribution and the effect of transcellular fluid shifts caused by changes in electrolyte levels. Simple, inexpensive devices to allow patients to track changes in their fluid status should be developed. The effect of varying the target time-averaged hydration status on morbidity and mortality should be studied so that volume control can become a measure of dialysis adequacy as suggested by Ok and Mees (Ok \& Mees, 2010).

For the majority of patients, interdialytic fluid gain can be controlled by using a standard low-normal dialysate sodium and keeping salt consumption to no more than $6 \mathrm{~g} /$ day. Staff will also benefit from keeping to this recommended salt intake. Patients who tolerate ultrafiltration very poorly will need careful management of sodium loading on dialysis together with a customised low-salt diet. An individualised approach, including improved diabetic control and motivational interviewing will also be required for patients with very low pre-dialysis serum sodium levels whose fluid intake does not depend on salt.

\section{References}

Brener ZZ, Kotanko P, Thijssen S, Winchester JF \& Bergman M. (2010) Clinical benefit of preserving residual renal function in dialysis patients: an update for clinicians. Am J Med Sci., Vol. 339 (2010), pp. 453-6.

Chamney PW, Wabel P, Moissl UM, Müller MJ, Bosy-Westphal A, Korth O, Fuller NJ. (2007) A whole-body model to distinguish excess fluid from the hydration of major body tissues. Am J Clin Nutr Vol. 85 (2007), pp. 80-89.

Charra B. (2007) Fluid balance, dry weight, and blood pressure in dialysis. Hemodial Int, Vol. 11 (2007), 21-31.

Davita. The hemodialysis diet. http://www.davita.com/kidney-disease/diet-andnutrition/diet-basics/the-hemodialysis-diet/e/5314 (accessed May 2011).

de Paula FM, Peixoto AJ, Pinto LV, Dorigo D, Patricio PJ \& Santos SF. (2004) Clinical consequences of an individualized dialysate sodium prescription in hemodialysis patients. Kidney Int, Vol. 66 (2004), pp. 1232-1238.

Gardiner C, Scott H, Wright M, Greaves E \& Lindley E. (2006) IDWG, salt and water - an audit of dialysis staff. British Journal of Renal Medicine, Vol. 11 No. 3 (2006), pp. 12-14. 
Healthy Eating Club. Sodium Food Charts. http://www.healthyeatingclub.org/info/ books-phds/books/foodfacts/html/data/data5a.html (accessed May 2011).

Henderson LW. (1980). Symptomatic hypotension during hemodialysis. Kidney Int, Vol. 17 (1980), pp. 571-576.

Jaeger JQ, Mehta RL. (1999) Assessment of dry weight in hemodialysis: an overview. J Am Soc Nephrol, Vol. 10 (1999), pp. 392-403.

Keen ML \& Gotch FA. (2007) The association of the sodium 'setpoint' to interdialytic fluid gain and blood pressure in hemodialysis patients. Int J Artif Organs, Vol. 30 (2007), pp. 971-9.

Kayikcioglu M, Tumuklu M, Ozkahya M, Ozdogan O, Asci G, Duman S, Toz H, Can LH, Basci A \& Ok E. (2009) The benefit of salt restriction in the treatment of end-stage renal disease by haemodialysis. Nephrol Dial Transplant, Vol. 24 (2009), pp. 956-962.

Lindley E, Devine Y, Hall L, Cullen M, Cuthbert S, Woodrow G \& Lopot F. (2005) A wardbased procedure for assessment of fluid status in peritoneal dialysis patients using bioimpedance spectroscopy. Perit Dial Int, Vol. 25. Suppl. 3 (2005), pp. S46-S48.

Lindley EJ, Stragier A, De Vos JY, Lahuis K, Shaldon S, Green D, McLaren P, Pegoraro M, Küntzle W, Tattersall JE \& López-Gómez J. (2005) Summary of the EDTNA/ERCA Journal Club discussion of López-Gómez et al (Kidney Int 2005) 'Interdialytic fluid gain as a marker of blood pressure, nutrition, and survival in hemodialysis patients'. EDTNA-ERCA Journal, Vol. 31 (2005), pp. 164-168.

Lopot F, Nejedly B, Novotná H, Macková M \& Sulková S. (2002) Age-related extracellular to total body water volume ratio (ECV/TBW) - can it be used for "dry weight" determination in dialysis patients? Application of multifrequency bioimpedance measurement. Int J Artif Organs, Vol. 25 (2002), pp. 762-769.

Marrón B, Remón C, Pérez-Fontán M, Quirós P \& Ortíz A. (2008) Benefits of preserving residual renal function in peritoneal dialysis. Kidney Int, Vol. 73 Suppl. 108 (2008), pp. S42-S51.

Machek P, Jirka T, Moissl U, Chamney P \& Wabel P. (2010) Guided optimization of fluid status in haemodialysis patients. Nephrol Dial Transplant, Vol. 25 (2010), pp. 538-544.

Mhurchu CN, Capelin C, Dunford EK, Webster JL, Neal BC \& Jebb SA (2011) Sodium content of processed foods in the united kingdom: analysis of 44,000 foods purchased by 21,000 households. Am J Clin Nutr, Vol. 93 (2011), pp. 594-600.

Middleton RA \& Allman-Farinelli MA. (1999) Taste sensitivity is altered in patients with chronic renal failure receiving continuous ambulatory peritoneal dialysis. J Nutrition, Vol 129 (1999), pp. 122-125.

Mitra S, Chamney P, Greenwood R \& Farrington K. (2004) The relationship between systemic and whole-dody hematocrit is not constant during ultrafiltration on hemodialysis. J Am Soc Nephrol, Vol. 15 (2004), pp. 463-469.

Moissl UM, Wabel P, Chamney PW, Bosaeus I, Levin NW, Bosy-Westphal A, Korth O, Müller MJ, Ellegård L, Malmros V, Kaitwatcharachai C, Kuhlmann MK, Zhu F \& Fuller NJ. (2006) Body fluid volume determination via body composition spectroscopy in health and disease. Physiol Meas, Vol. 27 (2006), pp. 21-33.

Ok E \& Mees EJ. (2010) Unpleasant truths about salt restriction. Semin Dial. Vol 23 (2010), pp. 1-2.

Penne EL, Levin NW \& Kotanko P. (2010) Improving volume status by comprehensive dietary and dialytic sodium management in chronic hemodialysis patients. Blood Purif, Vol. 30 (2010), pp. 71-78. 
Piccoli A, Rossi B, Pillon L \& Bucciante G. (1994) A new method for monitoring body fluid variation by bioimpedance analysis: the RXc graph. Kidney Int, Vol. 46 (1994), pp. 534-539.

Piccoli A, Nigrelli S, Caberlotto A, Bottazzo S, Rossi B, Pillon L \& Maggiore Q. (1995) Bivariate normal values of the bioelectrical impedance vector in adult and elderly populations. Am J Clin Nutr, Vol. 61 (1995), pp. 269-270.

Reddan DN, Szczech LA, Hasselblad V, Lowrie EG, Lindsay RM, Himmelfarb J, Toto RD, Stivelman J, Winchester JF, Zillman LA, Califf RM \& Owen WF Jr. (2005) Intradialytic blood volume monitoring in ambulatory hemodialysis patients: a randomized trial. J Am Soc Nephrol, Vol. 16 (2005); pp. 2162-2169.

Rupp JW, Stone RA \& Gunning BE. (1978) Sodium versus sodium-fluid restriction in hemodialysis: control of weight gains and blood pressures. Am J Clin Nutr Vol. 31 (1978), pp. 1952-1955.

Santos SF \& Peixoto AJ. (2008) Revisiting the dialysate sodium prescription as a tool for better blood pressure and interdialytic fluid gain management in hemodialysis patients. Clin J Am Soc Nephrol, Vol. 3 (2008), pp. 522-530.

Sezer S, Ozdemir FN, Arat Z, Perim O, Turan M \& Haberal M. (2002) The association of interdialytic fluid gain with nutritional parameters and mortality risk in hemodialysis patients. Ren Fail, Vol. 24 (2002), pp. 37-48.

Titze J. (2008) Water-free Na+ retention: interaction with hypertension and tissue hydration. Blood Purif, Vol. 26 (2008), pp. 95-9.

Tomson CR. (2001) Advising dialysis patients to restrict fluid intake without restricting sodium intake is not based on evidence and is a waste of time. Nephrol Dial Transplant, Vol. 16 (2001), pp. 1538-1542.

US Department of Agriculture. Sodium content of selected foods per common measure. http://www.nal.usda.gov/fnic/foodcomp/Data/SR18/nutrlist/sr18a307.pdf (accessed May 2011).

US National Heart, Lung, and Blood Institute. (2006) Your guide to lowering your blood pressure with DASH. http://www.nhlbi.nih.gov/health/public/heart/hbp/dash/ new_dash.pdf (accessed May 2011).

Van Biesen W, Williams JD, Covic AC, Fan S, Claes K, Lichodziejewska-Niemierko M, Verger C, Steiger J, Schoder V, Wabel P, Gauly A \& Himmele R; for the EuroBCM Study Group. (2011) Fluid status in peritoneal dialysis patients: the European Body Composition Monitoring (EuroBCM) study cohort. PLoS One, Vol. 6 (2011), e17148.

van der Wal WM, Noordzij M, Dekker FW, Boeschoten EW, Krediet RT, Korevaar JC \& Geskus RB; for the NECOSAD Group. (2011). Full loss of residual renal function causes higher mortality in dialysis patients; findings from a marginal structural model. Nephrol Dial Transplant, (2011). Epub ahead of print.

Vilar E, Wellsted D, Chandna SM, Roger N. Greenwood RN \& Farrington K. (2009) Residual renal function improves outcome in incremental haemodialysis despite reduced dialysis dose. Nephrol Dial Transplant, Vol 24 (2009), pp. 2502-2510.

World Health Organisation. (2010) Creating an enabling environment for population-based salt reduction strategies. Report of a joint technical meeting held by WHO and the Food Standards Agency, United Kingdom, July 2010. http://whqlibdoc.who.int/publications/2010/9789241500777_eng.pdf（accessed May 2011). 


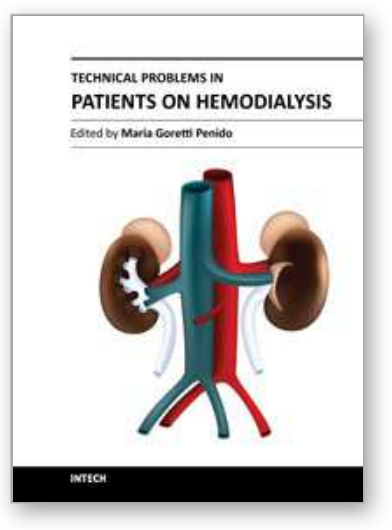

\author{
Technical Problems in Patients on Hemodialysis \\ Edited by Prof. Maria Goretti Penido
}

ISBN 978-953-307-403-0

Hard cover, 312 pages

Publisher InTech

Published online 07, December, 2011

Published in print edition December, 2011

This book provides an overview of technical aspects in treatment of hemodialysis patients. Authors have contributed their most interesting findings in dealing with hemodialysis from the aspect of the tools and techniques used.Each chapter has been thoroughly revised and updated so the readers are acquainted with the latest data and observations in the area, where several aspects are to be considered. The book is comprehensive and not limited to a partial discussion of hemodialysis. To accomplish this we are pleased to have been able to summarize state of the art knowledge in each chapter of the book.

\title{
How to reference
}

In order to correctly reference this scholarly work, feel free to copy and paste the following:

Elizabeth Lindley, Lynne Aspinall, Claire Gardiner and Elizabeth Garthwaite (2011). Management of Fluid Status in Haemodialysis Patients: The Roles of Technology and Dietary Advice, Technical Problems in Patients on Hemodialysis, Prof. Maria Goretti Penido (Ed.), ISBN: 978-953-307-403-0, InTech, Available from:

http://www.intechopen.com/books/technical-problems-in-patients-on-hemodialysis/management-of-fluid-statusin-haemodialysis-patients-the-roles-of-technology-and-dietary-advice

\section{INTECH}

open science | open minds

\section{InTech Europe}

University Campus STeP Ri

Slavka Krautzeka 83/A

51000 Rijeka, Croatia

Phone: +385 (51) 770447

Fax: +385 (51) 686166

www.intechopen.com

\section{InTech China}

Unit 405, Office Block, Hotel Equatorial Shanghai

No.65, Yan An Road (West), Shanghai, 200040, China

中国上海市延安西路65号上海国际贵都大饭店办公楼405单元

Phone: +86-21-62489820

Fax: $+86-21-62489821$ 
(C) 2011 The Author(s). Licensee IntechOpen. This is an open access article distributed under the terms of the Creative Commons Attribution 3.0 License, which permits unrestricted use, distribution, and reproduction in any medium, provided the original work is properly cited. 